\title{
Meeting family planning needs of factory workers in Port Said: Lessons from pilot testing an intervention in eight garment factories [Arabic]
}

Maryam Essam

Population Council

Nahla G. Abdel-Tawab

Population Council

Elizabeth Tobey

Population Council

Aparna Jain

Population Council

\section{Recommended Citation}

Essam, Maryam, Nahla G. Abdel-Tawab, Elizabeth Tobey, and Aparna Jain. 2021. "Meeting family planning needs of factory workers in Port Said: Lessons from pilot testing an intervention in eight garment factories [Arabic]," Policy brief. Washington DC: Population Council, The Evidence Project. 


\section{دمج خدمات الصحة الانجابية ونتظيم الأسبرة

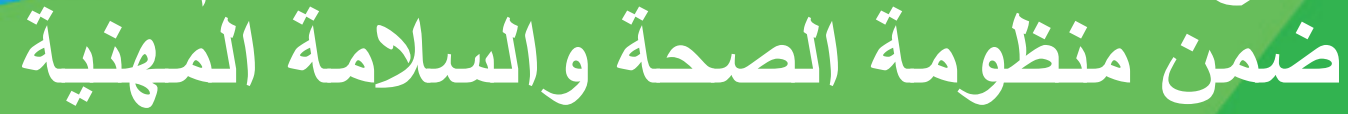

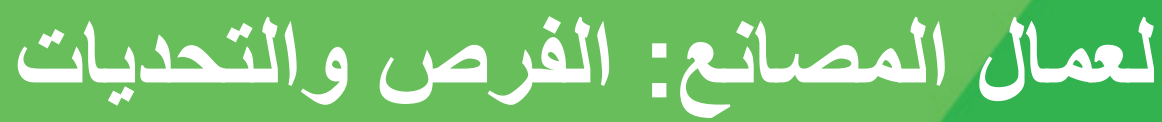

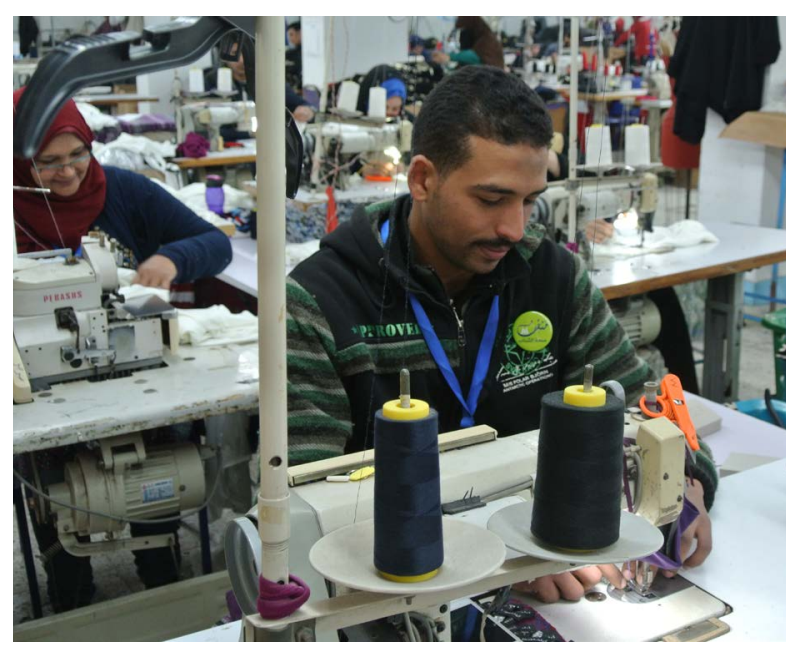

وتثنير بيانات الجهاز المركزى للتعبئة العامة

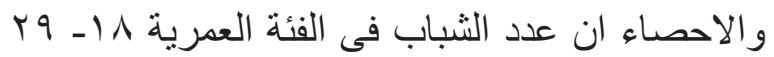

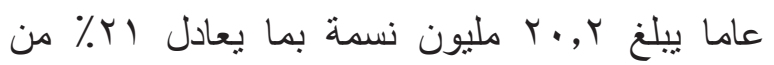

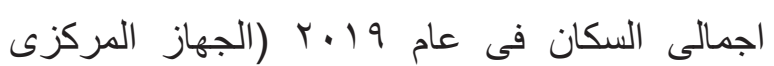

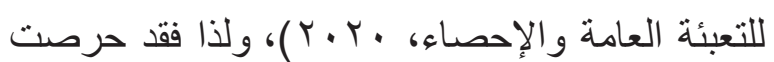
الدولة المصرية عند وضع الاستر اتيجية القومية للسكان

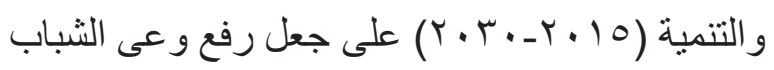

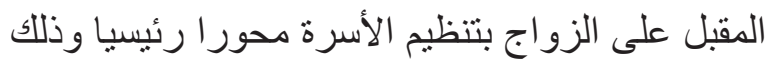

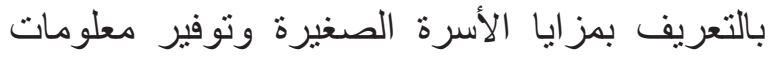

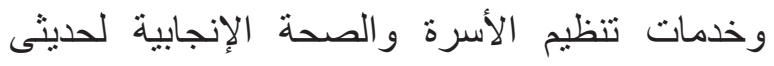

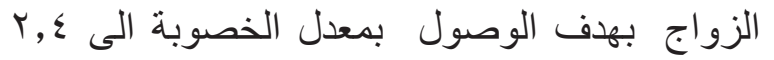

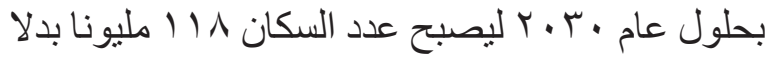

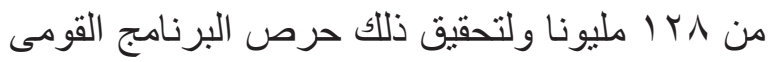

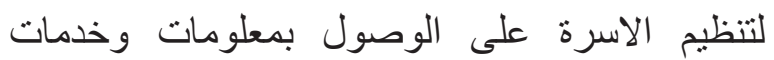

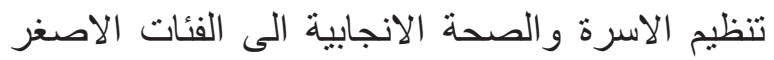

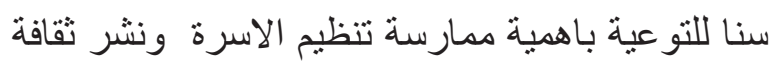

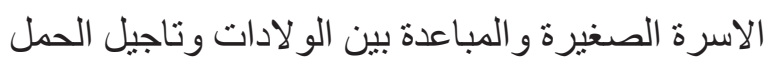
الاول للحفاظ على صحة الام و الطفل.

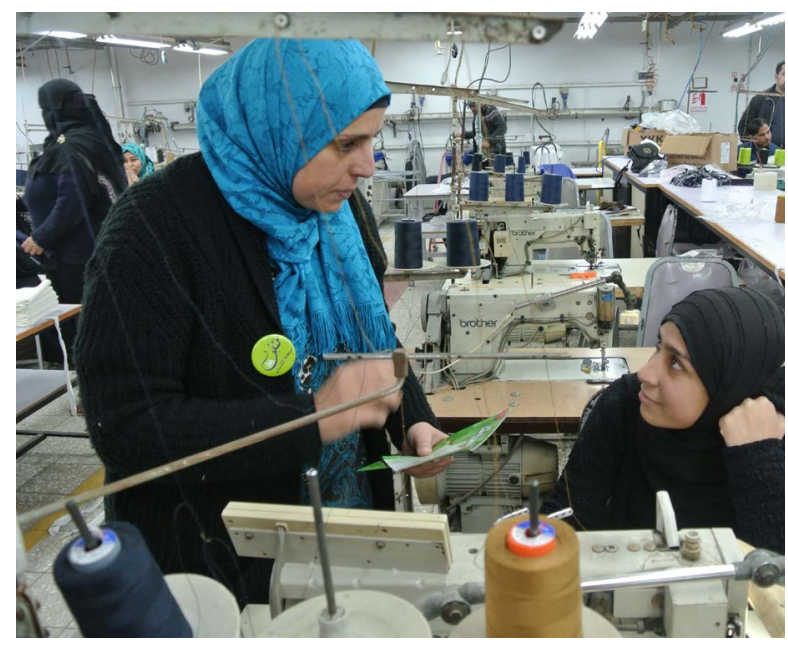

خلقية

شهدت مصر ارتفاعاً في معدل الانجاب خلال الفترة من

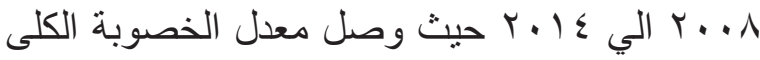
r,0 مولود في المتوسط لكل سيدة حسب المسح السكانى الصحى - مصر ع ا •r. (وزارة الصحة والسكان،

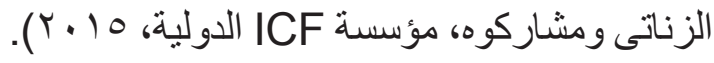
كما اظهر ملخص بحثى قام باعداده مجلس السكان الدولى حول تفضيلات وسلوكيات الانجاب بين الثباب

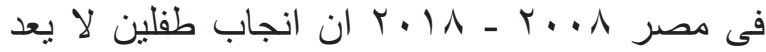

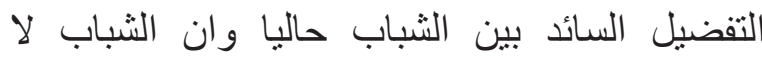
يفضلون استخدام وسائل تتظيم الاسرة قبل انجاب الطفل الاول. واظهر البحث ان هناك اعتقاد خاطئ بان استخدام وسائل تنظيم الاسرة يؤثر سلبا فى القدرة

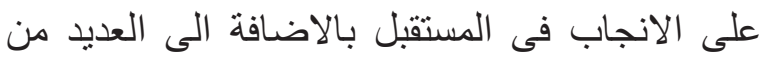
المفاهيم الخاطئة المتعلقة بالاثار الجانبية لوسائل

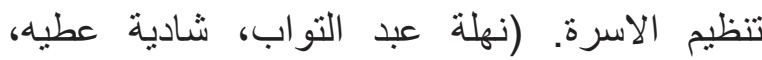

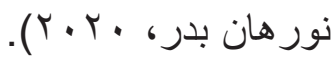




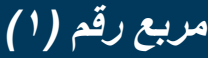

مشروع لاتعزيز دور التطاع الثاص فى تقليم خدمات الصحة الانجابية للشباب فى مصره":

قام مجلس السكان الدولى بالتعاون مع جمعية بورفؤاد الداد لرعاية الاسرة والطفل وبدعم من الوكالة الالة الامريكية

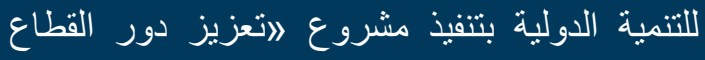
الخاص فى تقديم خدمات الصحة الانجابية للشباب فى مصر "، و المعروف بـ مشروع لاصحة الثبابه"

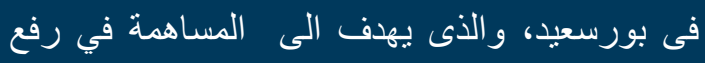

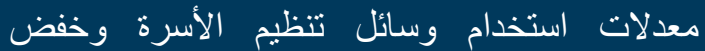
معدلات الخصوبة، عن طريق زيادة رفع الوعي اللعاملين بالمصانع وتحسين جودة تقديم خدمات الصحة الصدة الإنجابية وتنظيم الأسرة

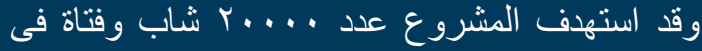

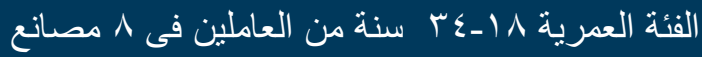
بالمنطقة الاستثمارية في بورسعيد وقد قام المشروع برفع وعى هؤلاء العمال من خلال مثئقى الأقران

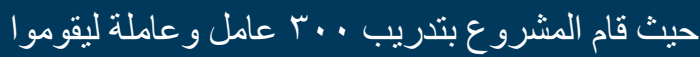

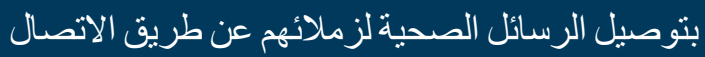
المباشر مع الاستعانة بالمواد الإعلامية ووسائل

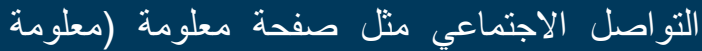
التنظيم الأسرة Ma3loma) على الفيس بوك وارسال الرسائل الصحية على الواتس اب.

كما قام المشروع بتعزيز دور الممرضة بعيادة المصنع بحيث تقوم بنقديم المشورة عن تنظيم الاسرة

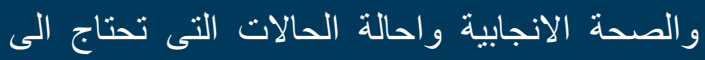
خدمة طبية الى مقدمى خدمات القطاع الخاص وقال

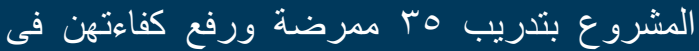

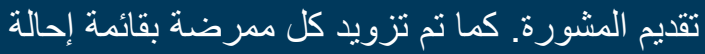

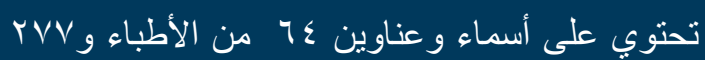
من الصبادلة المدربين من قبل المشروع.

ولتحقيق الاستدامة قام المشروع بتشكيل لجنة صحية بكل مصنع تكون مسئولة عن تحديد احتياجات العمال و ادارة ومتابعة برامج الصحة بالهصنع. كما تم الثناء

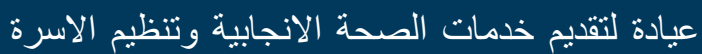
بدعم من مؤسسة اتصالات وجمعية المستثرين بالمنطقة الحرة ببورسعبد.
وتركز حملات التوعية على مجموعات مختلفة من الثباب منها طلاب المدارس و والجامعات و والمجندين و غير هم. وتمثل فئة عمال المصانع شريحه هامة يمكن التهاب

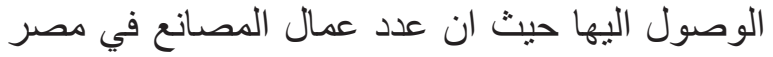

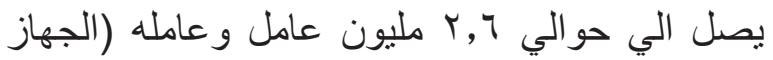

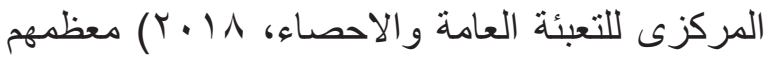
في سن الانجاب. وتمثل نسبة النساء في بعض القطاء القطاعات

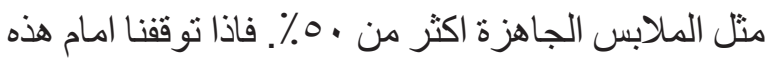

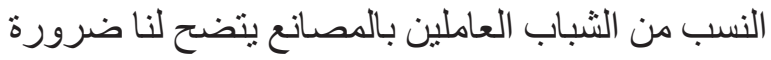

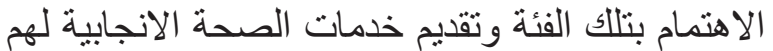
من خلال رفع الوعي وتقديم الخدمات الطبية.

وقد قام مجلس السكان الدولي بتتفيذ مشروع لاتعزيز دور القطاع الخاص فى تقديم خدمات الصحة الانجابية الصابية للثباب فى مصر / لتلبية احتياجات الصحة الانجابية وتنظيم الاسرة للثباب من عمال المصانع بالمنطقة

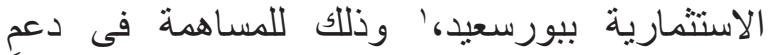

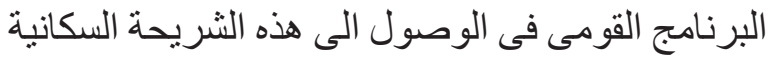

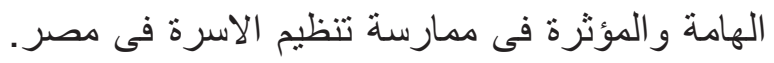
(انظر المربع رقم المعرفة المزيد عن المشروع).

وتهدف هذه الورقة الي استعراض الانماط المختلفة لتقديم معلومات وخدمات الصحة الانجابية لعمال المصانع ضمن برامج صحة العمال استتادا الي تجربة الاتية مجلس السكان الدولي والعديد من الابحاث و والدراسات و واسترشادا باراء عدد من المختصين والمعنيين في هذا

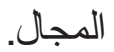

\section{لماذا دمج الصحة الانجابية ضمن برامج صحة العمال؟ دماذج}

تمثل النساء في العديد من القطاعات الصناعية نسبة

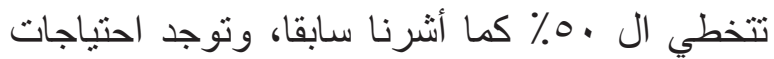

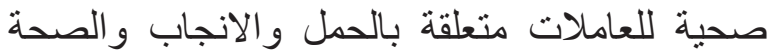
الانجابية (مثال متاعب الدورة الثهرية) وغير ذلكاتل كما توجد احتياجات ايضا للعمال من الذكور تنعلق بنص المعلومات و الدفاهيم الخاطئة المتعلقة بالصحة التحكة 
مكونات خدمات الصحة الإنجابية وتنظيم الأسرة فى برامج صحة العمال:

يمكن ان يتم تقديم خدمات الصحة الانجابية للعمال عن طريق رفع الوعي الصحي او تقديم خدمة طبية او

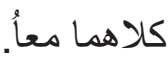

• رفع الوعي الصحى: يعد رفع وعى العمال ونشر الصر

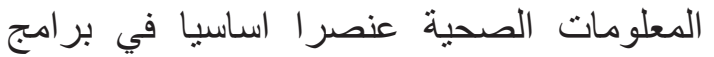
صحة العمال لزيادة معرفتهم وثقافتهم ونشر الشر السلوكيات الصحيحة فيما يتعلق بالحمل و الانجاب و تنظيم الاسرة و غير ها من الموضو عات. ويمكن

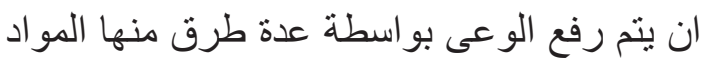

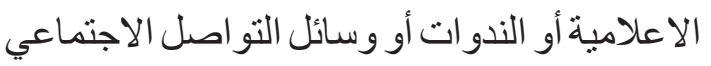

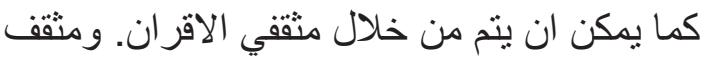
الأقران هو عامل أو عاملة في المصنع يتم تدريبهر

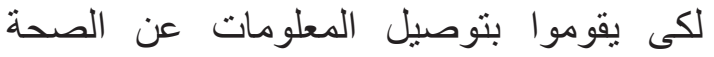
العامة و الصحة الانجابية وتنظيم الأسرة لزملائهر وتصحيح الأفكار المغلوطة، كما انهم يقوموا لدابله بدور حلقة الوصل بين زملائهم والفريق الصحي بالمصنع أو المنشاة التي يعملون بها.

وقد وجد من خلال تجربة مجلس السكان الدولي المنمثله في المشروع المشار اليه في المربع رقم أن مثقف الأقران الجيد هو من لديه شعور بالمسئولية تجاه زملائه، ومؤمن بأهمية الصحة الانجابية

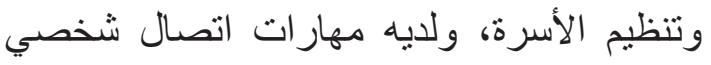

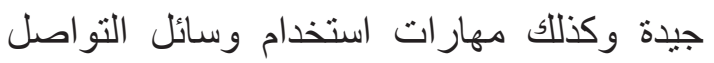
الاجتماعي المختلفة. كما يفضل ان يكون من ون الحاصلين على مؤهلات تعليمية متوسطة او عليا،

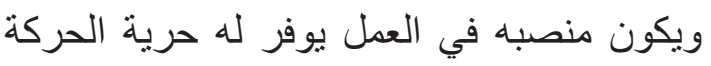

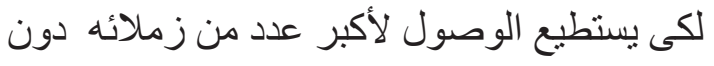

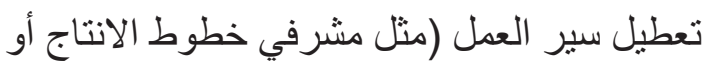

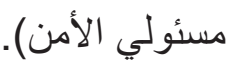

كما اظهر المشروع اهمية اشرالك المديرين ومشرفي الانتاج بالمصنع في تصميم انشطة رفع

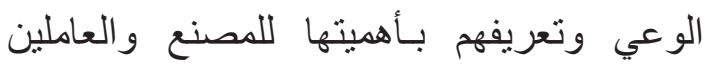
به للمشاركة في وضع وضع الاليات و القواعد التي ولفي تتظم عمل مثقفي الاقران مثل تحديد مو اعيد نقل
الانجابية وتنظيم الاسرة وهو ما يؤثر سلباً على صحتهم

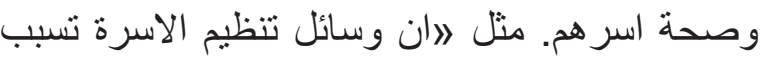

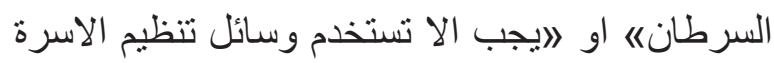
قبل إنجاب عدد كافي من الأطفال لأنها تسبب العقمها. كما ان اعتلال الصحة الإنجابية وتكر ار الحمل والولادة

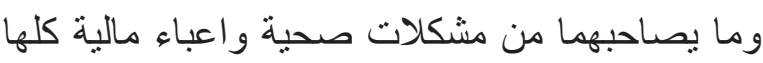
اسباب يمكن ان تؤدي الي خفض الانتاجية وزيادة

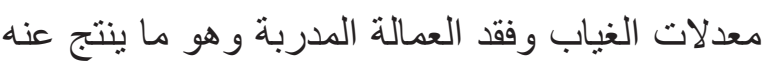
خسارة مالية للمنشأة.

كل الاحتياجات السابقة يمكن تلبيتها وتفادى النتائج

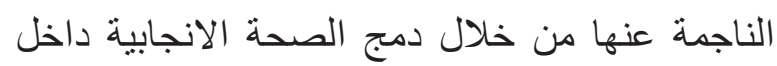

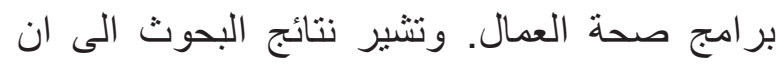

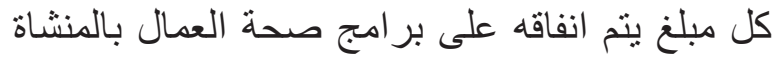

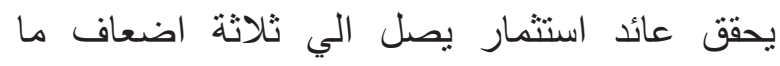
تم انفاقه وذللك من خلال الارتقاء بصحة العاملين

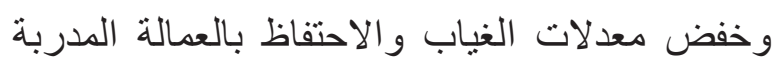

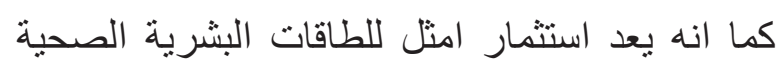
بالمنشأة (Baicker, Cutler \& Song, 2010).

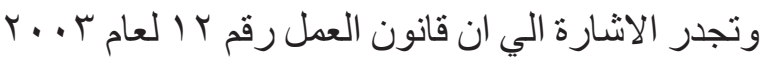
يضع من ضمن اشتر اطات الصحة و السلامة المهنية

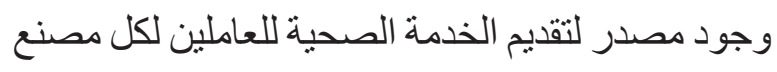
او منشاة يصل عدد العاملين بها الى خمسين او اكثر، لذا يعتبر دمج خدمات الصحة الانجابية وتتظيم الاسرة

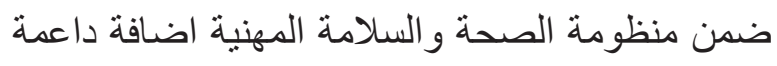
لتحقيق اهداف تللك المنظومة. (انظر المربع رقم ؟).

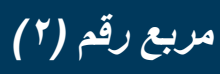

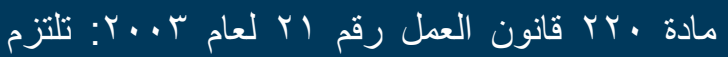

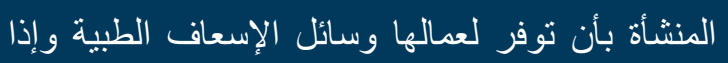

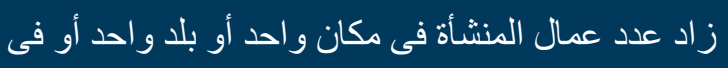
دائرة نف قطر ها خمسة عشر كيلو متر العلى خمسين

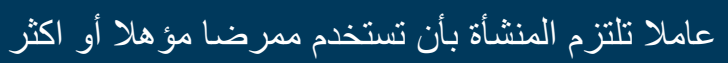
لأعمال التمريض أو الإسعاف بكل وردية علفية عمل بها، وأن تعهد إلى طبيب بعيادتهم فى المكان الذى تعده لهذا

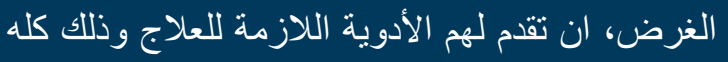




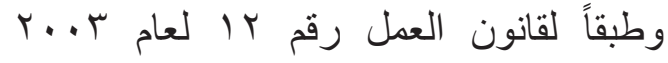

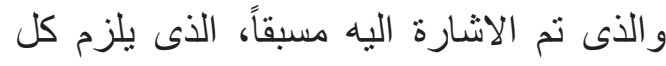

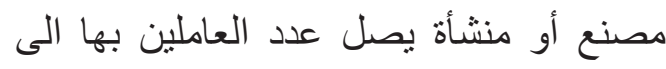
خمسين او اكثر، بتوفير مكان (عيادة) لتقديم

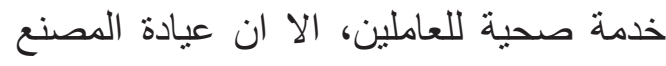
غالباً ما تقوم بدور محدود مثل تقديم الإسعافات

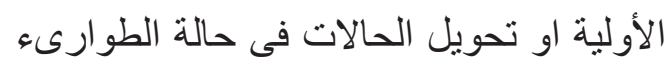
أو للحصول على خدمات صحية من الجهات

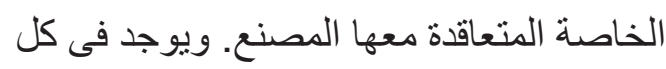
مصنع ممرضة منو اجده بصورة منتظمة يومياً وكذلك طبيب في ايام محددة من الأسبوع. ويمكن تفعيل دور العيادة و الممرضة بتدريبها ورفع كفاءتها لتقديم مشورة خاصة دورئ عن الصحة الإنجابية وتنظيم الأسرة للعاملات المترددات

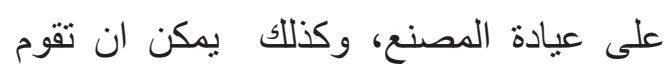
باحالة العاملات اللاتى يرغبن في الحئ وكصول على خدمة طبية الى طبيب خارجى يمكن ان يتعاقد معه المصنع.

وقد استخدم مجلس السكان الدولى وجمعية بور فؤاد لر عاية الاسرة و الطفل هذا النموذج لتقديم الخدمة فى المشروع (المشار اليه فى المربع رقم ( )، وقد اتضح من خلال تتفيذ هذه التجربة التئ

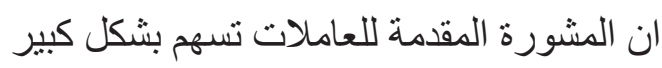
فى رفع و عيهن وتصحيح العديد من المعلومات المغلوطة لديهن ومساعدتهن فى اختيار الطبيب

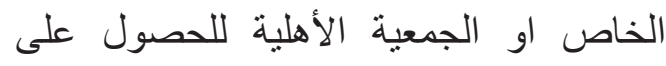
الخدمة الطبية بأسعار مناسبة لهن.

الا ان ارتفاع معدل دوران طاقم التمريض في

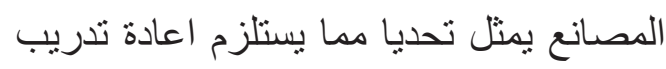

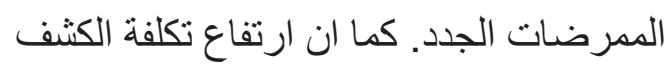

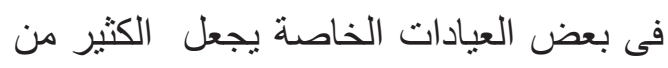

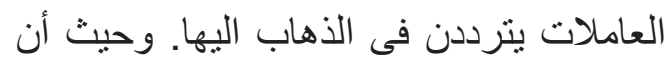
معظم العاملات يقمن في محافظات اخرى في لون ومن ثم لا يستفدن من شبكة الاطباء المتعاقد
الرسائل واماكنها وكذللك اختيار مثقفي الاقران من بين العمال التي تتسم وظائفهم بالاستدامة في ولئي

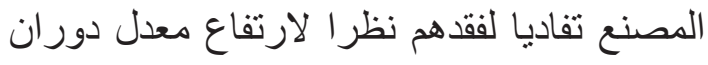

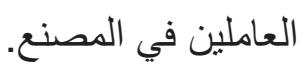
• ثقديم خدمة طبية: ويفضل ان يصاحب رفع الوعى تقديم خدمة طبية بجودة وكفاءة عالية

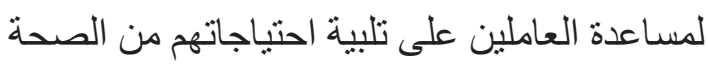

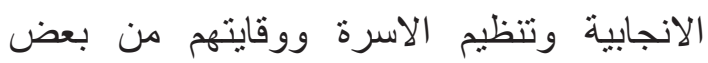
المشاكل الصحية. ويمكن تقديم خدمات الصحة وتهة الانجابية وتتظيم الاسرة بصور مختلفة منها:

\section{- العيادات المتنقلة التابعة لوزارة الصحة} والسكان وذللك بالتنسيق مع مديرية الثئون الصحية بالمحافظة وفقا لجدول معلوم مسبقاً

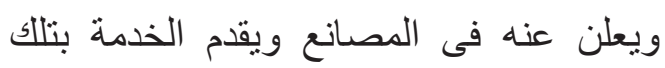

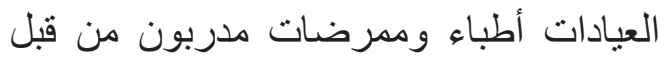

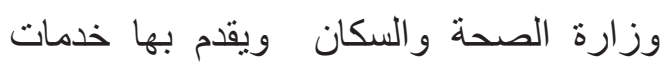
الكثف والمشورة ورسائل تنظيم الأسرة بالمجان. وقد سبق ان قامت مديرية الثئون

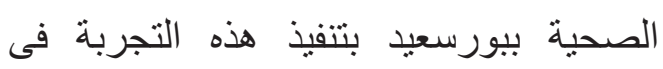
المنطقة الاستثمارية ببورسعيد. ليورسيا لئهيد.

والجدير بالذكر ان تقديم هذه الخدمة لا يشكل اى عبء مالى أو ادارى أو مسؤلية فنية

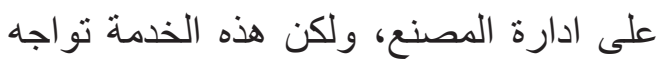
بعض التحفظات من المستفيدات من عاملات

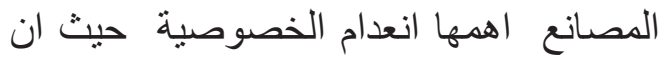

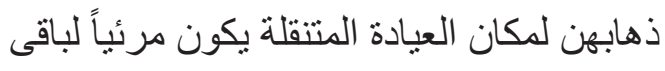

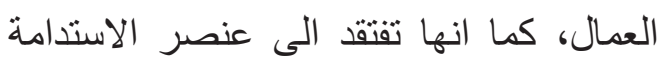

$$
\text { واستمرار المتابعة. }
$$

ومن ثم يجب اختيار مكان مناسب للعيادة المتنقلة يتسم بالخصوصية مع ترنيب زيار ات

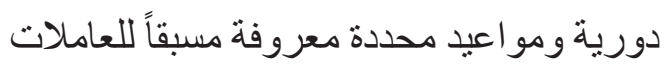
للتغلب على تلك التحديات.

تقديم المشورة الخاصة بتنظيم الأسرة والصحة الإنجابية بواسطة ممرضة المصنع والاحالة الى جهات خارجية للحصول على الخدمة 


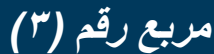

تخصמي

\section{مركز} (عيادرة تنظيم أسرة) بالمصنع: بتسبين

يقدم طلب الترخيص الي النقابة الفر عية للاطباء مرفق به الاوراق التالية:

• طلب مطابقة التصديق على اسم المركز معنمد من النقابه. صورة عقد الايجار او التمليك.

صور كرنبهات الاطباء العاملين بالمركز صورة من شهادة الاخصائي اوالاسثناري المدير الفني الصادرة من النقابة.

صورة من عقد الاتفاق بين المدير الفني و الاطباء الصسادرة من النقابة.

رسم هندسي معتمد من مهندس معماري مقيد في سجلات نقابة المهندسين.

تصوير فوتو غر افي للافته على واجهة العمارة من زاويتبن مختلفين وذلك بعد موافقة النقابة على بيانات اللافته دفع رسم المعابنة بالنقابة الفر عية. تقدم جميع الأور اق للنقابة الفرعية. لا بجوز للمدير الفنى أن بكون مديرا فنيا لأى

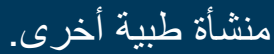

بعد الإنتهاء من التسجيل بتم التوجه إلى مديرية الصحة التابع لها العبادة لانهاء اجر اءات التسجيل و التعاقد على التخلص من النفايات وسداد الرسوم.
- تقديم خلمة صحية متكاملة بالمصنع

و المقصود هو تقديم خدمة الصحة الإنجابية وتتظيم الأسرة بعيادة المصنع وبواسطة طبيب متخصص (طبيب نساء وتوليد) يتو اجد بعيادة المصنع اما بعض الوقت أو كل الوقت مع توفير وسائل تتظيم الاسرة بعيادة المصنع.

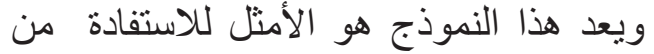
العيادة وطاقم التمريض والطبيب، كما انه بسهل حصول العاملات على الخدمة في مكان العمل وبسعر رمزي مع ضمان استمرارية الحصول عليها. ولكن هذا النموذج بتطلب وجود عدد كبير من العاملين بالمصنع حتى ونى

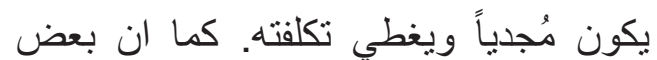
اصحاب المصانع ابدى تحفظه على النموذج خوفا من المسئولية التي يمكن ان تقع عليهم التئح في حالة حدوث اي مضاعفات تنتج عن تقديم

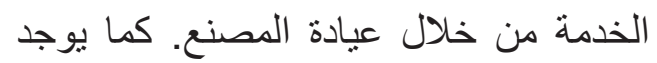
تخوف من ان يؤثر وجود العيادة على سير العمل على اعتبار ان فترات الراحة والغذاء قد تكون غير كافية للذهاب الى العيادة وتلقي اعني

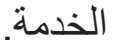

وقد اتضح من خلال تجربة مجلس السكان

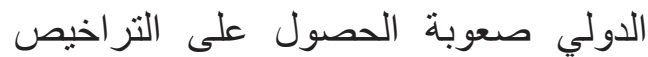
اللازمة لتسجيل العيادة حيث تخضع عيادات

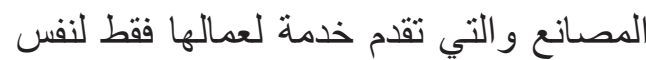
اجر اءات الترخيص للعيادات التي تقدم خدمة للعامة كما هو موضح فى المربع رقم (ب). ويمكن التغلب على بعض الصعوبات السابقة من خلال تقديم الخدمة الصحية المتنقلة بحيث يتم التنسيق والتعاون بين مديرية الثئون

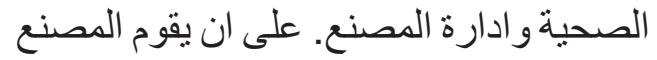
بتجهيز العيادة لتكون صالحة لتقديم خدمات تنظيم الاسرة وان تقوم المديرية بتوفير وسائل تنظيم الاسرة ومقدمي الخدمة وترتيب مو اعيد زيار ات دورية لهم لتقديم الخدمة لعمال

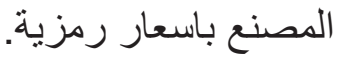


r. انشاء لجان بالمصانع تتولى ادارة ومتابعة بر امج

الخحلاصة

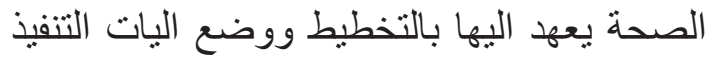
و المتابعة وتحديد احتياجات العمال و عقد الثر اكات

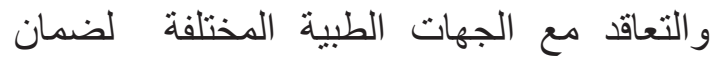
الاستمر ارية في تقديم الخدمة.

ع. تقوم وزارة الاستثمار والاتحاد العام للصناعات

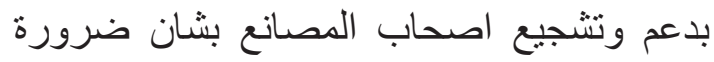
توفير الخدمات الصحية (بما فى ذلك خدمات تنظيم الاسرة والصحة الانجابية) للعاملين بالمصانع مع تقديم التسهيلات والحوافز اللازمة لأصحاب لابه

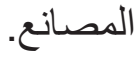

๑. يمكن التنسيق والتعاون بين المصانع الموجودة

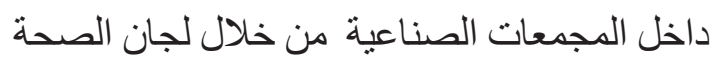

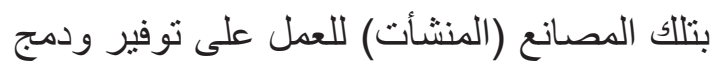

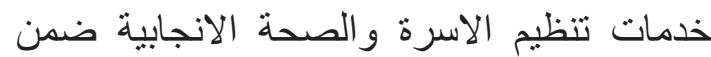
حزمة الخدمات الصحية الاخرى التي تقدم للعمال بتلك المصانع و الوصول الى نموذج متميز لتقديم الخدمة بما يناسب ظروف تللك المصانع.

بعتبر اتاحة خدمات تنظيم الاسرة والصحة الانجابية للعاملين بالمنشآت الصناعية (عمال المصانع) تدخلا استراتيجيا للوصول الى قطاع كبير من الثباب فى بـ

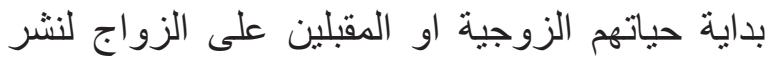

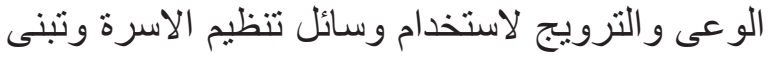
مفهوم الاسرة الصغيرة ومن ثم فهو يساعد فى تتفيذ الاستر اتيجية القومية للسكان.

ويوجد نماذج متعددة لدمج خدمات الصحة الإنجابية

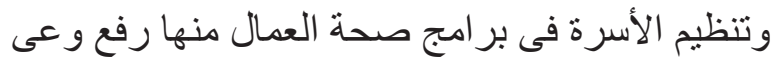
العمال أو تقديم الخدمة الطبية عن طريق برامج العربات المتنقلة، وتقديم المشورة والاحالة أو انشاء عيادة

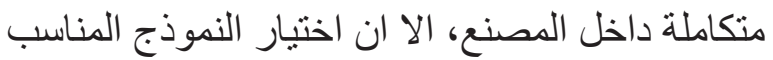

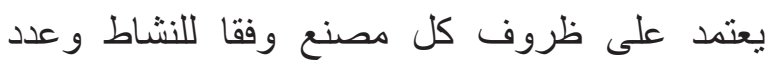
العاملين وظروفهم و احتياجاتهم.

\section{التوصيات}

7. رفع وعى اصحاب المصانع بأهمية دمج خدمات

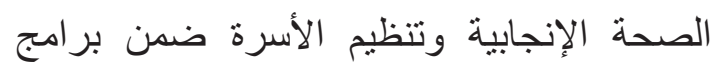

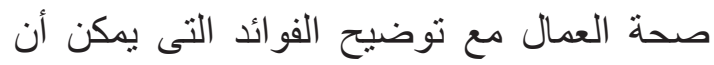
تعود عليهم و على المصنع. V . تشجيع الجمعيات الاهلية التى تقدم خدمات تنظيم

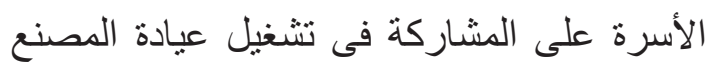
وتقديم خدمات الصحة الإنجابية وتنظيم الأسرة ،

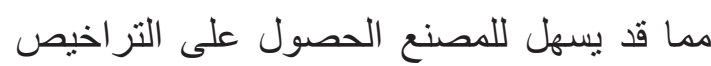

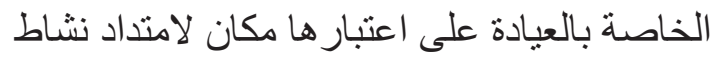
الجمعية. كما انه يتيح الحصول على وسائل تنظيم الأسرة المدعمة من وزارة الصحة.

ا. تتبنى وزارة الصحة والسكان فكرة دمج خدمات تنظيم الاسرة والصحة الانجابية ضمن منظومة

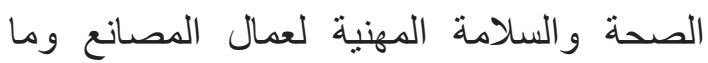
يسلتزم ذلك من تشريعات واجر اءات و المساهمة في توفير العيادات المتنقلة ومقدمى الخدمة ووسائل تنظيم الاسرة. r. التنسيق بين الجهات المسئولة عن تراخيص

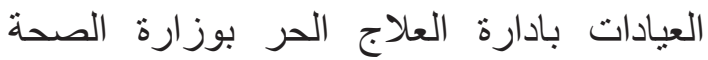

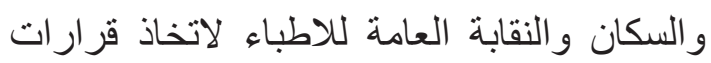
لاتمام اجر اءات ترخيص عيادات المصانع و العمل العل على تيسير تللك الاجر اءات. 


$$
\begin{aligned}
& \text { الجهاز المركزى للتعبئة العامة والاحصاء، التعداد }
\end{aligned}
$$

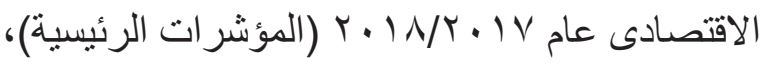

$$
\begin{aligned}
& \text { مصر 11 ا. r. }
\end{aligned}
$$$$
\text { المراجع باللغة الانجليزية }
$$

Baicker K, Cutler D, Song Z.

Workplace wellness programs can generate savings. Health Aff (Millwood). 2010 Feb;29(2):30411-. doi: 10.1377/ hlthaff.2009.0626. Epub 2010 Jan 14. PMID: 20075081.

\section{الإستشهاد المقترح:}

مجلس السكان الدولى. ا Y . . . دمج خدمات الصحة الانجابية وتتظيم الأسرة ضمن منظومة الصحة

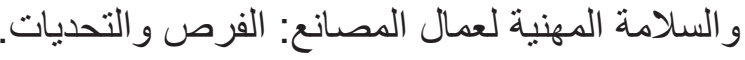
ورقة سياسات. القاهرة، مصر : مجلس السكان

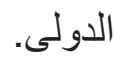

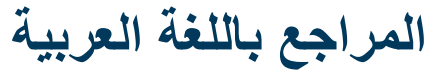

وزارة الصحة والسكان (مصر)، الزناتى

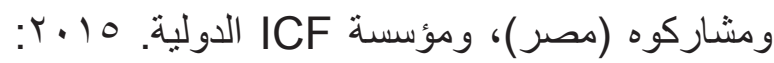

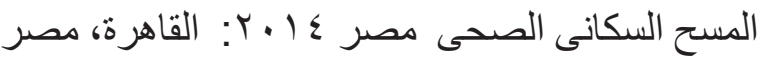
روكفيل، ميريالند، الواليات المتحدة الأمريكية، وزارة المئه

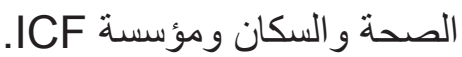

نهلة عبد التواب وشادية عطيه ونورهان بدر.

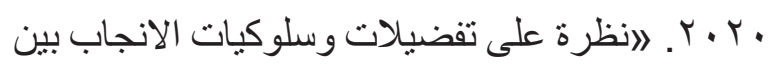

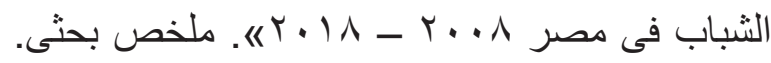
القاهرة، مصر : مجلس السكان الدولى. مئ.

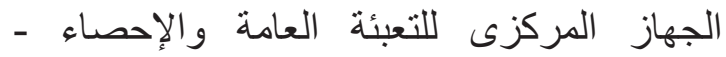
إصدار ات ربع سنوية - النشرة: مجلة إحصاء مصر

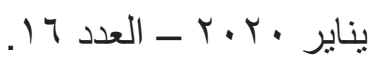

https://www.capmas.gov.eg/

Pages/Publications.aspx?page $\underline{\mathrm{id}=5106 \& \text { Year }=23435}$

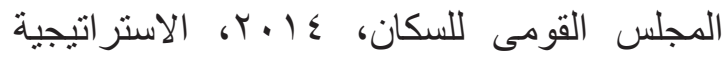

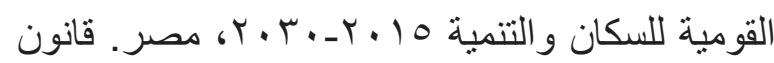

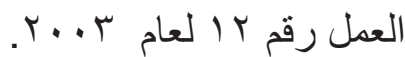

https://www.manpower.gov.eg/PDF/

WorkLow/law2003.pdf

تم اعداد هذه الورقة ضمن انشطة مشروع لاتعزيز دور القطاع الخاص فى تقديم خدمات الصحة الانجابية للثباب فى مصر الذى يقوم بتنفيذه مجلس السكان الدولى بدعم من الوكالة الامريكية للتنمية الدولية. يتقدم مجلس السكان الدولى بخالص الثكر للاكتور حسام عباس رئيس قطاع السكان وتنظيم الأسرة

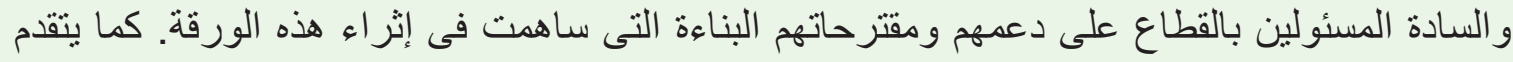
المجلس بجزيل الثكر للاكتور مجدى خالد استشارى أمر اض النساء والتوليد والصحة الإنجابية لاسهاماته

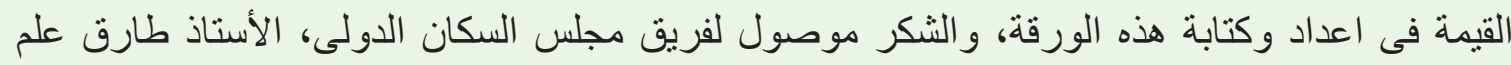

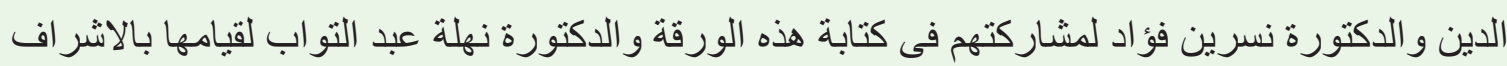
العام و المر اجعة. 


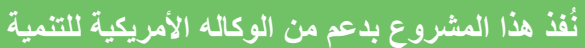

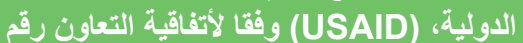
AID.OAA.A.13-00087

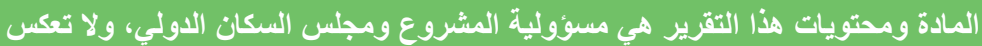

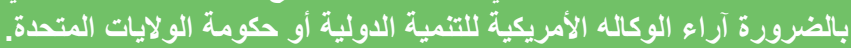

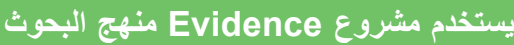

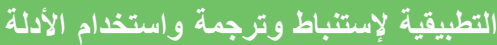

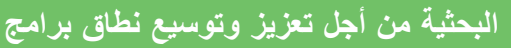

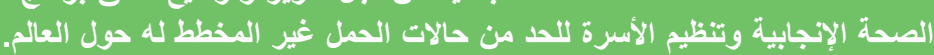

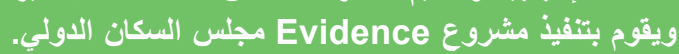

THE EVIDENCE PROJECT

$$
\begin{aligned}
& \text { مجس السكان الدولى }
\end{aligned}
$$

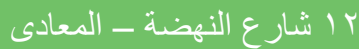

$$
\begin{aligned}
& \text { | | }
\end{aligned}
$$

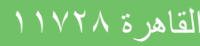

$$
\begin{aligned}
& \text { هاتف: rMONIVY }
\end{aligned}
$$

Evidence evidenceproject@popcouncil.org

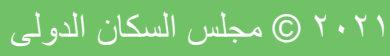

